\title{
Accessible Tailgating: An Examination of ADA Requirements and Implications Associated With Tailgating Activities
}

\author{
Andy Gillentine, John Grady, \\ John J. Miller, and Karen Pettus
}

\begin{abstract}
Tailgating activities have been often positively connected to sports events. However, despite nearly 57 million individuals with disabilities that possess more than $\$ 200$ billion of annual discretionary spending in the United States, research regarding accessibility to tailgating activities by individuals with disabilities has been lacking. Illustrative of the evolution of the scope of the Americans with Disabilities Act of 1990, this article addresses the legal obligations as required by the ADA and other related laws as well as potential risk management recommendations to minimize legal issues concerning accessible tailgating. Using legal research methodology, significant issues of concern included the lack of institutional monitoring of the tailgate area and a disregard of parking issues for individuals with disabilities.
\end{abstract}

As a result of the Americans with Disabilities Act's (ADA) mission to guarantee full inclusion into the mainstream of American life for all persons with disabilities, people with disabilities now experience greater access to sport facilities and services (Grady \& Andrew, 2007) and sport participation rates have increased (McCormick, 2000). While novel legal challenges still arise that continue to test the boundaries of the ADA and legitimate barriers to full participation still exist (Devine \& McGovern, 2001), the overall fan experience for people with disabilities has improved.

During what could be called the "dark days" before the ADA's passage and implementation of other related civil rights laws and regulations for persons with disabilities, the level of accessibility at stadiums was not uniform across venues and often presented spectators with few options for an equivalent fan experience similar to what people without disabilities experience (Paramio-Salcines, n.d.). Today, however, a confluence of factors has gradually over time resulted in an enhanced fan experience for people with disabilities. These factors include a clear legal mandate since 1990 and specific legislative guidance in the form of federal accessibility guidelines (ADAAG, 2000) and updated ticketing regulations (2010 ADA Standards for Accessible Design, 2010). In addition, these factors are targeted toward specific industry sectors including sports, cultural arts, and entertainment

Gillentine (agillentine@hrsm.sc.edu) and Grady are with the Department of Sport and Entertainment Management, University of South Carolina. Miller is with the School of Hospitality, Sport, and Tourism Management, Troy University. Pettus is with the Office of Student Disability Services, University of South Carolina. All authors contributed equally to this manuscript. 
venues, and include improved training by front-line staff, and commitment by senior management to work toward creating a more accessible environment for fans (Paramio-Salcines, Downs, \& Grady, in press).

The overall experience at sporting events for people with disabilities has been improving and the goal of providing a truly accessible and enhanced fan experience seems within reach at some aspirant sport venues. Yet, depending on the layout and configuration of each specific venue, notably stadiums, related to areas nearby such as parking, not all areas of the "gameday" experience may be as fully accessible for people with disabilities as the physical aspects of the interior of venue itself. This creates an opportunity to analyze how to improve both the safety and customer experience for fans with disabilities while they are participating in tailgating activities. A scholarly examination into equality in tailgating opportunities and safety for patrons with disabilities at sport venues, therefore, can be viewed as a "future issue" in the evolution and genesis of the ADA's impact in sport venue and event management.

Tailgating has become an integral component of the sporting and entertainment event environment. Fans from all demographics and of all sports, from Little League Baseball to NASCAR, can be found socializing at tailgating parties that take place in stadium, arena and private parking lots before sporting events. Although a variety of sports and entertainment events have adopted tailgating as a critical element of enhancing the fan experience, none have embraced and incorporated tailgating into its core fabric as has collegiate football (Miller \& Gillentine, 2006). Tailgating serves as an ideal setting to meet participants' desire for social interaction, togetherness, excitement and escape as indicated in previous research examining tailgating (Gillentine, 2003; James, Breezeel \& Ross, 2001). As such, event marketers and entrepreneurs have capitalized on the popularity of tailgating and use it as a tool to help promote and market events (Gillentine \& Miller, 2015; Gillentine, Miller, \& Calhoun, 2008).

While no research has been conducted to indicate the number of individuals with disabilities who partake in tailgating activities, the most recent data indicates that $22 \%$ of Americans have at least one disability, with mobility impairment being the most common type (Centers for Disease Control, 2015). As consumers, people with disabilities in the United States contribute more than $\$ 200$ billion in discretionary spending (Brault, 2012). Such discretionary spending ability aligns itself with a recent focus on the economic implications of tailgating activities (Brown, Gillentine, \& Grady, 2011; Gillentine \& Miller, 2015). As a result, it is intuitive to conclude that a fair population of tailgaters at sporting events with the motives and the resources to participate may also be a person with a disability afforded protection under the ADA.

When universities encourage tailgating as a means of building community and support for the athletic department, not only must they ensure that individuals with disabilities have an equal opportunity to access and participate in all aspects of the tailgating experience (defined under Title II of the ADA as "program access" for public universities), they must also ensure that issues including physical location, parking, and restrooms, among other requirements, are also accessible. According to the experience of Karen Pettus, Director of Disability Services at the University of South Carolina, students with disabilities often generally discuss their inability to access the stadium. Students have also indicated they often avoid tailgating areas 
due to perceived safety concerns as well as the added stress of getting from the tailgating location to the stadium (personal communication, October 29, 2015).

Every event is unique and therefore offers different challenges that event organizers must address. Best practices recommend a stadium accessibility policy for persons with disabilities be developed which would include access to tailgate areas. The policy and a list of accessible facilities, features, and services should be disseminated well before the start of the season on the university's and/or athletic department's web site (Grady \& Finnegan, 2012). Previous research indicates that published tailgating policies were vague or nonexistent among intercollegiate athletic programs (Miller \& Gillentine, 2006). Quite often, existing policies do not provide the specific insight or depth needed to deal with the myriad of issues that can occur in conjunction with tailgating at an event. Individuals who partake in tailgating activities usually do not act in a criminal manner, yet the potential for legal implications for event organizers abound (Wong, 2002). An example of a patron with a disability being caught up in a dangerous situation at a sporting event is evident in the case of a North Carolina State student. The student, Will Privette, a wheelchair user, was involved in a celebratory "rush the court" incident after North Carolina State defeated Duke University. Privette was unintentionally knocked from his wheelchair as other celebrating students rushed the court. According to Privette, "It was like a wave. It toppled me over" (Walsh, 2013). While this scenario is different, an argument could be made that a person with a disability could be involved in a similar situation with celebrating fans in a tailgating area.

\section{Background}

Among the reasons that people with disabilities often do not visit places of public accommodation include architectural and transportation barriers (H.R. Rep. No. 101-485, Pt. 2, 1990) or safety concerns (Grady \& Finnegan, 2012; Pate, Bemiller, $\&$ Hardin, 2010). Financial constraints in providing additional programs, services, and equipment for people with disabilities, as well as a lack of awareness among professional staff of the needs of people with disabilities provide additional hurdles (Devine \& McGovern, 2001; Rimmer, 2005). For example, the opportunity to attend a sports event with the knowledge that safe and abundant parking is available for a driver with a disability may provide greater opportunities for involvement at a sports event.

While tailgating can be a major part of a positive "Game Day" experience for team supporters, it may be vastly diminished if the event managers overlook meeting the needs of individuals with disabilities, including both older and younger fans with disabilities. For example, while many athletic departments and universities recognize and support organizations such as the Wounded Warrior Project during the season, the question must be addressed: "Is the same level of attention and support being provided by the venue's event managers to ensure these patrons have an accessible and safe game day experience which includes tailgating?" In addition, as it relates to university students as potential attendees, according to the U.S. Department of Education (2013), the OCR is responsible for ensuring students with disabilities full participation in every facet of educational life, including access to athletic events. However, if the event management staff overlooks these aspects of safety and accommodation of fans with disabilities attending tailgating activi- 
ties, they may be in violation of Title II or Title III of the American Disabilities Act (ADA) of 1990.

\section{Purpose of the Study}

Current research has indicated that despite the positive attributes associated with tailgating, problems do exist (Gillentine, 2003; Gillentine \& Miller, 2006; Gillentine et al., 2008; Gillentine, Miller \& Crow, 2010). Current standards and regulations do not provide guidance on how best to prepare for the safe inclusion of people with disabilities in the tailgate environment (2010 ADA Standards for Accessible Design, 2010). In light of the growing diversity among sport consumers, the question that must be explored is: Does accessible and safe tailgating exist for individuals with disabilities? More specifically, the purpose of this study was twofold: 1) to determine the legal obligation to provide accessible tailgating to people with disabilities and, 2) determine the best way to provide this service to fans. To examine these issues, it is important to establish a) the need for such investigation, b) the relationship of tailgating to ADA regulations and other applicable legal obligations c) current risk management event standards and their relationship to tailgating and accessibility and d) recommendations to minimize liability associated with accessible tailgating.

\section{Legal Research Approach}

Legal research is an iterative process that requires analyzing multiple and competing legal sources to confirm a legal trend (Moorman \& Grady, 2011). To begin the legal research process, since this study was focused on tailgating at college sporting events, a search of the Association of Higher Education and Disability (AHEAD) Database of Disability-related Cases and Rulings was conducted. The database is composed of lawsuits and rulings and letters from the Office of Civil Rights and the U.S. Department of Education Family Policy Compliance Office from the early 1990s to the present (i.e., during the same period of time when the ADA has been in force). Only one result involving sport stadiums was found: a complaint involving accessibility of donor parking surrounding Williams Brice stadium at the University of South Carolina. Recent media coverage has also indicated relatively recent complaints over inadequate or absent stadium captioning in the stadium itself at the University of Kentucky, University of Maryland, University of Maryland at College Park, and Ohio State University (Schoepfer-Bochicchio, 2013).

No specific cases dealing with the issue of tailgating and people with disabilities (as students or consumers from the general public) were found. The lack of findings can be interpreted in several ways. First, because ADA enforcement is a complaint-driven process (Leuchovius, 2007), people with disabilities may not be filing official complaints with the Office of Civil Rights (OCR) when they feel they have been subjected to discriminatory treatment in violation of the ADA. This complaint triggers an investigation of the complaint by OCR. An alternative explanation is that, even in cases against a university where a spectator has complained about stadium access, the complaint is resolved privately (through the university agreeing to make the requested accommodation) and does not result in a formal complaint being filed with OCR. Both of these resolution methods would 
likely not result in any kind of litigation or "case" that would produce a judicial opinion. It is also likely many ADA cases are often settled between the parties, thus few details are available beyond a mere initial mention in a local newspaper or on a disability rights blog. Thus, a thorough review of multiple legal resources and risk management "best practices," directed at locating any instances involving tailgating had to be performed.

Information to determine legal obligations and risk management practices to provide accessible tailgating was collected from various legal resources, including applicable federal laws, law reviews (through a Lexis Nexis search), a disability resource database search (AHEAD) which includes complaints involving colleges and universities, and peer reviewed academic studies in the areas of disability issues in sport management and tailgating risk management. By integrating and analyzing various sources in an iterative way, the researchers were able to identify the legal obligations that exist and begin to understand how sport organizations can provide accessible and inclusive tailgating that is both safe for people with disabilities (as well as people without disabilities) and enhances the fan experience for all.

\section{The ADA and Tailgating Activities}

To guard against potential premises liability claims and meet the legal requirements of the ADA, event management staff must be aware of their responsibilities to those fans with both visible or invisible disabilities who partake in tailgating activities before, during, and potentially after a sport contest. An understanding of the duties to create and maintain a reasonably safe environment and to adhere to the ADA regulations, particularly as stipulated in Title II and Title III, is essential.

\section{Title II of the ADA}

Title II of the Americans with Disabilities Act of 1990 prohibits disability discrimination by government entities by providing that "no qualified individual with a disability shall, by reason of such disability, be excluded from participation in or be denied the benefits of the services, programs, or activities of a public entity, or be subjected to discrimination by any such entity" (42 U.S.C. $\$ 12132$ ). Under Title II, college personnel must ensure that individuals with disabilities have physical access to facilities and an equal opportunity to participate in and benefit from all programs and activities offered to students, faculty, staff and guests of the university. The term "public entity" includes any state or local government and their departments, agencies, special purpose districts, or other instrumentalities (42 U.S.C. $\S 12131(1))$. Title II's wide scope encompasses public colleges and universities that often promote (and occasionally coordinate) tailgating and related pregame activities as part of their unique game day experience for students and alumni. The obligation to make such pregame events and spaces accessible flows logically from the same legal obligations that apply to activities within the stadium.

\section{Title III of the ADA}

Title III of the Americans with Disabilities Act of 1990 prohibits discrimination on the basis of disability by places of public accommodations. According to the ADA 
Accessibility Guidelines (ADAAG, 2000), within Title III, it is asserted that "[a] public accommodation shall afford goods, services, facilities, privileges, advantages and accommodations to an individual with a disability in the most integrated setting appropriate to the needs of the individual. .." (28 C.F.R. § 36.203(a)). The ADAAG (2000) defines a facility as "all or any portion of buildings, structures, sites, complexes, equipment, rolling stock or other conveyances, roads, walks, [and] passageways, parking lots . .” (28 C.F.R \$35.104). As a result, the priority of a public accommodation must provide access from public sidewalks and parking lots, including providing accessible parking spaces (28 C.F.R. $§ 36.304(c)(1)$ ). Accordingly, the ADAAG states:

This priority on 'getting through the door' recognizes that providing actual physical access to a facility from public sidewalks, public transportation, or parking is generally preferable to any alternative arrangements in terms of both business efficiency and the dignity of individuals with disabilities (28 C.F.R. pt. 36, App. B.).

Regarding individuals with disabilities' access to goods, services, and employment opportunities on an equal basis with the general public, reserved parking and specialized treatment are necessary items. The significance of accessible and ample parking for a driver with a disability is a vital prerequisite for the place of public accommodation.

Parking Accommodations. Parking accommodations are not the only considerations covered by Title III of the ADA as a person with a disability may drive or use a van for transportation to accommodate a wheelchair. Previous studies have indicated that the sponsoring organization must be cognizant of their legal duties to tailgaters, including addressing risk management issues in parking lots (Gillentine, et al., 2010; Miller \& Gillentine, 2006). According to Pate et al., (2010), "accessible parking at athletic events, specifically college football games, is an area that is not commonly disputed in the legal system" (p. 4).

Reserved parking and specialized accommodations pursuant to the ADA, such as game day shuttles for patrons with disabilities, may be necessary to allow individuals with disabilities access to facilities, service programs, and activities on an equal basis with the general public (Pate et al., 2010). Despite numerous overlapping legal requirements, as discussed in depth below, Miller and Gillentine (2006) reported that over $75 \%$ of the institutions did not possess risk management strategies that regulated the size, placement or way a vehicle may be parked. In a study by Stone (2007), the three most common shortcomings regarding parking issues for individuals with disabilities were that $69 \%$ of parking areas were not compliant with regard to the access aisle, $38 \%$ were deficient in signage designation and $30 \%$ did not have proper access routes. Because there are no traffic lights or pedestrian walk signs in a tailgating area, the lack of signage for cars and vans creates uncertainty and confusion for both drivers with and without disabilities. Both for the driver without a disability to respect and avoid parking in the accessible parking space and to permit easy access and parking for the driver, signage is of the utmost importance. Stone (2007) found that in twenty percent of the lots, no appropriate signage was present. Especially as it relates to accessible tailgating, the lack of signage for cars and vans creates uncertainty and confusion for drivers. 
The ADA also requires reasonable modification of policies and procedures so that individuals with disabilities can take full advantage of the offerings of the tailgate experience. While parking lot availability close to the stadium often raises concerns and has triggered lawsuits by donors trying to enforce their rights based in contract law rather than on ADA grounds (Norman, 2012), some of these areas may be controlled by private booster groups that require seniority to purchase these spaces. A more frequently occurring issue may arise since some individuals with disabilities have oversized vehicles and may require additional space to park. A poorly crafted parking policy may therefore inadvertently require individuals with disabilities to pay more for the experience to tailgate than other able-bodied patrons pay.

Accessibility Issues. According to Pate et al., (2010), "large scale on-campus events like Division I football games force universities to use numerous lots of different sizes and characteristics across the campuses for parking" (p. 4). While these commercial facilities are required to provide access under Title III of the ADA (as places of public accommodation), providing parking for football games may not be the intended primary use of the facilities and therefore may not be accessible for use in tailgating. It should be noted that tailgating accessibility for people with disabilities also would be applicable to older patrons who want to participate in tailgating and would create new revenue streams if the tailgate environment meets their needs (Grady, Andrew, Mercado, \& Blevins, 2015).

Although the college may not own the facility or be able to make modifications to a facility that they do not own, colleges are not exempt from providing accommodations for patrons with disabilities when using (i.e., leasing) space that is owned by a nongovernmental agency. The legal obligation to provide an accessible experience and accommodate the patron is still present. The protections afforded by the ADA may also come back into play and trigger additional legal obligations, such as obligations found in premises liability, to ensure a safe environment for tailgating for people with disabilities and people without disabilities. The owner/ operator or supervisor of the "event" has an affirmative duty, per the ADA, to ensure that services are provided to individuals with disabilities in a nondiscriminatory manner and must not be denied the full and equal enjoyment of the goods, services, and facilities (42 U.S.C. $§ 12182$ ).

\section{Premises Liability Issues}

While the ADA has several specific provisions that are directly applicable to tailgating events, as detailed above, there are also other areas of law that are significantly implicated when considering how best to provide access to tailgating for individuals with a disability. These additional legal obligations can be thought of as working in tandem with disability-specific civil rights laws to close any "gaps" that might exist to help ensure a safe and accessible environment. Specifically, premises liability is "the body of law which makes the person who is in possession of land or premises responsible for certain injuries suffered by persons who are present on the premises" (American Lawyer Directory, 2015, para. 1). Premises liability initiates certain legal obligations to protect patrons from unreasonable danger on the land (Grady, 2013). With regard to tailgating, the scope of legal protection owed is dependent on the individual's purpose in entering and using the land where tailgating occurs. 
Since tailgating occurs in a range of settings, some of which require patrons to pay to enter, the legal obligations could vary widely. For example, in a situation where owning and operating tailgate lot(s) is the primary business and the operator is charging patrons a per-game or seasonal fee to park and tailgate in the lots, the patrons would be considered business invitees and owed the highest duty of care. However, there are a myriad of examples of how contemporary tailgating occurs. For example, consider a large-scale tailgate event coordinated by a university's athletic department, where marching bands and/or players parade through and promotional activities often occur near a stadium. This event is often open to the public and does not charge for admission.

A complicating factor when it comes to tailgating at college sports events is premises ownership. While many colleges and universities may own the land on which the major tailgating activities take place, they may not own the land located close to their stadium on which ancillary tailgating activities occur. Instead these colleges or universities may contract with private entities to use this property for parking during football season. Generally speaking, the landowner or operator owes a duty to keep the premises safe for all who enter (Grady, 2013). More specifically, the premise owner or operator must "exercise reasonable care to protect the invitee from an unreasonable risk of harm caused by a dangerous condition on the land" (Bertrand v. Alan Ford, 1994, p. 606, 609). Furthermore, a "safe" facility or sporting event is foreseeably safe for participants, spectators, staff, and visitors (Seidler, 2005).

Foreseeability Issues. Considering the unique needs of individuals with disabilities while tailgating, determining what, if any, additional legal obligations are required to provide a safe environment becomes a challenge. According to the court in McPherson v. Tennessee Football Incorporated (2007), premises liability requires an owner or operator of land to protect its customers from probable or foreseeable dangers and noted that this duty has been extended to supervision of athletic events (emphasis added). In determining what is a probable and foreseeable danger, however, the fact-finder must consider the condition of the premises, not the condition of the plaintiff (Mann v. Shusteric Enterprises, 2004, involving an intoxicated bar patron who slipped on ice and snow in the bar's parking lot). Moreover, while premise owners have a duty to protect invitees from unreasonable risks of harm caused by dangerous conditions on the land, "they are not absolute insurers of the safety of their invitees" (Quinlivan v. The Great Atlantic \& Pacific Tea Co, Inc., 1975, p. 261). When considering these fundamental legal principles in toto, it can be concluded that accommodating individuals with disabilities in a tailgating environment does not trigger additional premise liability obligations to protect individuals with disabilities any differently than other patrons are protected. The legal analysis does not end there, however.

One must also consider the type of activity occurring on the property. For example, the activity may be considered "unreasonably dangerous" to the extent that the premise owner or operator to provides some additional risk mitigation measures beyond warning notices. These additional measures could include providing roving security patrols or additional lighting in the tailgate lots for a night event. The basis for such responsibility is grounded in the concept of foreseeability. The facility owner/operator must "anticipate foreseeable uses and activities by invitees and take reasonable precautions to protect the invitees from foreseeable dangers [that] 
takes into consideration the normal uses of the facility and frequently occurring incidents or activities by patrons" (Grady, 2013, p. 136). Among the most notable foreseeable dangers of tailgating activities are the overuse of alcohol by patrons, the resulting violent behavior of others, and the lack of security supervision that may place a person with disability in harm's way (Bearman v. University of Notre Dame, 1983).

Heavy alcohol consumption would be a prime example of a foreseeable danger which may frequently occur during tailgate events. Since tailgating may be considered part of the typical atmosphere often found when attending intercollegiate football games, it would be reasonable for the landowner (i.e., university/college) to anticipate that intoxicated actions of some tailgaters may endanger others (Bearman v. University of Notre Dame, 1983). Prior investigations have indicated that drinking alcohol can increase an individual's violent tendencies, especially when placed in an emotionally charged atmosphere such as attending sport contests (Harford, Wechsler, \& Muthen, 2003).

A recent example of such behavior occurred in 2014 when a brawl between tailgating fans from the University of Texas-El Paso and Texas Tech University erupted in a tailgate area (Staff report, 2014). Reportedly, fans of both teams had been drinking alcoholic beverages in the tailgating area. According to a tailgater involved in the fight, "I ran in and saw some guy on the floor. I tried to get some people off of him and I guess I ended up tackling some guy and when I tried to get up, I was attacked" (Staff report, 2014, para. 4). If a similar situation involved a person who is blind or a wheelchair user who was participating in tailgating activities, it is foreseeable that the person with a disability could be significantly injured.

Danger to a Vulnerable Population and Lack of Supervision. According to Ruof (2004) individuals with disabilities represent an overlooked, yet potentially vulnerable population. Legally speaking, specific focus of any lawsuit involving people with disabilities being injured while tailgating would be based in tort law for the landowner's failure to provide additional security protection for a "vulnerable population" who they should have known (based on past experience) may be in the tailgate environment. According to the World Health Organization (2015), vulnerable individuals have difficulty anticipating, coping with, resisting and recovering from a negative impact such as an injury. As mentioned earlier, sports contests provide an emotionally charged atmosphere. In some cases, the emotions extend to violent behaviors between fans of different teams (Harford et al., 2003) which could impact other people in the tailgate space who are less able to protect themselves from harm.

Knowledgeable individuals of well-run organizations should try to manage potential event risks or they may become controlled by the risk (Frame, 2003). The specific liabilities and duties discussed provide an indication of the essential legal responsibilities of an organization or individual sponsoring tailgating activities, particularly toward individuals with disabilities. This information may aid sport event managers in understanding the importance of the development and implementation of a risk management plan.

\section{Risk Management Practices}

According to a university director of disability services, students with disabilities have expressed safety and accessibility concerns about attending tailgating activities 
(Pettus, personal communication, October 29, 2015). A viable way in addressing such concerns is through the effective communication of a risk management plan (Grady \& Finnegan, 2012; Miller \& Gillentine, 2006). While Grady and Finnegan (2012) indicated that risk management policies, including tailgate policies, should be communicated well-before the start of the season on the university's and/or athletic department's web site, Miller and Gillentine (2006) revealed that a majority of Division I universities were unclear regarding tailgating hours or supervision of the tailgate areas.

Event organizers are under no duty to protect competitors from the inherent risks associated with their activities (Dobbs, 2000). However, event managers have a duty of care or responsibility to protect others from third party harm, or to warn others of threats posed by third parties (Rotolo v. San Jose Sports and Entertainment, 2007). Although they may not be aware of the liability involved, it is possible that one can argue that event managers are bound by law to protect from potential threats and therefore be held accountable if they shirk that duty (Dobbs, 2000; Piccarello, 2005).

Since many primary tailgating parties take place in parking lots associated with the university, the university, as the landowner, has the duty to monitor the premises (Restatement of Law (Second), Torts, 1969, § 344). Monitoring under these circumstances is not meant to create an atmosphere in which tailgaters cannot enjoy themselves, instead it should provide an environment in which an attendee with a disability is not exposed to unnecessary harm. Traditional risk management approaches are likely to overlook the interconnectivity of many organizational risks (Miller, Wendt, \& Young, 2010). A risk management plan should be measured in regards to its association to overall organizational policy, risk policy and to the interconnectivity that exists between risks (Miller et al., 2010). As such, the management of the risks that may be highly applicable to a person with a disability might be affected not only by the design and construction of tailgating areas but by marketing policies (i.e., fan friendly or kid zone), general financial considerations (i.e., revenue production), as well as facility maintenance and management.

The case can be made that effective risk management contributes to organization value (Williams, Smith, \& Young, 1998). In regards to people with disabilities attending tailgating parties before a sports event, the value of the event would seem to be the result of an interconnected range of "experience elements," such as ambience, security, and the ability to interact with friends and family members. Taken in this light, the decision to develop and implement a risk management plan must fully consider both the "value" dimension and the legal dimension.

As event environments have become more complex (financially, legally, culturally), the need for a systematic methodology for the conducting of the events has become more apparent (O'Toole, 2000). Since there are no common risk management plans for tailgating activities at the university level (Miller \& Gillentine, 2006), the current system of patchwork guidelines and policies leaves tailgate event managers in a vulnerable position in terms of potential litigation. Thus, it is imperative that the operator or supervisor of the tailgate event has a management team that is knowledgeable about risk management in addition to understanding the complexity of legal obligations. This information may aid sport event managers in understanding the importance of the development and implementation of a best practices risk management plan. 


\section{Best Practice Risk Management Recommendations for People With Disabilities at Tailgate Activities}

Because significant injuries to an individual with a disability attending tailgate activities have not been previously litigated, a university or college athletic department may not have understood the need for developing, implementing, and communicating a risk management plan to ensure a reasonably safe environment. For example, the university could identify specific event personnel to communicate ADA-related issues to those attending the tailgating activity in real-time (Grady \& Paramio, 2012). Risk management, when properly developed, implemented, and communicated, may be perceived as a fundamental way in which decision-makers address potential issues (Miller et al., 2010). Following a best practices risk management plan allows for appropriate decisions to be made quickly and increase the capability to communicate these decisions to all personnel involved (O'Toole, 2000). In addition, best practices risk management models further allow for the development of programmed decisions to be implemented that ensures consistency of the oversight of the tailgating activities (Gillentine et al., 2010).

The emotional atmosphere at sports contests sometimes lends itself to fans fighting. As such, particularly if fueled by alcohol consumption, such incidents may not be an issue for people without disabilities but may put a person with a disability in a precarious situation of injury. In addition, environmental as well as concession issues must be addressed as they apply to individuals with disabilities who attend tailgating activities. The following recommendations should be considered when developing a best practices risk management plan for individuals with disabilities attending tailgating activities:

1. Increase the number of accessible parking enforcement and supervision staff. Depending upon the location of the event, tailgate host organizations need to carefully analyze the possible interactions with such agencies and immediately make initial contacts

2. Educate all staff members about the state law requirements for accessible parking

3. Educate all staff members regarding environmental factors (i.e., heat, cold, rain, etc.) that may become extremely dangerous for people with disabilities

4. Increase the number of signs to identify accessible parking areas, particularly for van parking. It is crucial that designated tailgating areas are clearly recognizable and marked for the public. This designation will help organizers implement their supervisory system and enforcement

5. Provide sufficient signage identifying proper access routes. The demarcation of these areas can lead to more efficient parking utilization and safer pedestrian traffic in case of emergencies

6. Provide sufficient signage identifying the locations of restrooms or porta-potties in the tailgating area

7. Develop extensive and detailed written information for persons with disabilities and make this information available in advance of the season on the university's and/or athletic department's web site 
8. Designate a point-person within the event management team to manage ADArelated issues in real-time at the event

9. Train student groups about providing accessible tailgating events to ensure that gluten free foods, nut free foods, and dairy free foods are available and avoid cross contamination of foods when food is provided by a student group.

\section{Conclusion}

Judge Oliver Wendell Holmes (1881/1963) is credited with saying that the life of the law has not been logic; it has been experience. Although, there has not been any previous case law examples of a person with a disability being injured in a tailgating activity, the brawl involving fans from Texas Tech University and the University of Texas-El Paso highlights the lack of monitoring that should be conducted by the home university's security personnel. Event managers should proactively communicate foreseeable risks including alcohol, parking and accessibility issues as well as provide appropriate number of security personnel to monitor the area.

In conclusion, determining whether a tailgate experience satisfies the legal obligations and is truly accessible, a broader inquiry is needed that goes beyond determining if the land upon which the tailgating occurs can be accessed by a person with a disability. Identifying shortcomings with regard to access can be done in cooperation with a local group of supporters with disabilities who might offer reasonable and cost-effective solutions once barriers are identified. Based upon research findings and popular demand for tailgating and tailgating related activities, sport event managers can expect the potential participation in and expectations of tailgating events and activities to continue to grow. As more individuals participate in tailgating activities, it is reasonable to expect that the number of individuals with disabilities who desire to participate will also increase. Thus, event managers of tailgate events should be responsive to reasonable (legal) requests to modify or develop policies if the reason for the modification of the policy is due to disability.

\section{References}

2010 ADA Standards for Accessible Design. (2010). United States Department of Justice. Retrieved from http://www.ada.gov/2010ADAstandards_index.htm

ADA Accessibility Guidelines (ADAAG), 28 C.F.R. 36.406, Appendix A (2000).

American Lawyer Directory. (2015). Premises liability. StateLawyers.com. Retrieved from http://www.statelawyers.com/Practice/Practice_Detail.cfm?PracticeTypeID=77

Americans With Disabilities Act of 1990, Pub. L. No. 101-336, §2, 104 Stat. 328 (1990).

Bearman v. University of Notre Dame, 453 N.E.2d 1196 (Ind. Ct. App. 1983).

Bertrand v. Allan Ford, Inc., 449 Mich. 606. (Mich. 1995).

Brault, M.W. (2012). Americans with Disabilities: Household economic studies. U.S. Department of Commerce Economics and Statistics Administration. Retrieved from http:// www.census.gov/prod/2012pubs/p70-131.pdf.

Brown, M., Gillentine, A., \& Grady, J. (2011). Underestimating economic impact: An analysis of overlooked event attendees. Madrid, Spain: European Association for Sport Management. 
Centers for Disease Control and Prevention. (2015). Prevalence of disability and disability type among adults - United States, 2013. Morbidity and Mortality Weekly Report, 64(29), 777-783. doi:10.15585/mmwr.MM6429a2

Devine, M.A., \& McGovern, J. (2001). Inclusion of individuals in public park and recreation programs: Are agencies ready? Journal of Park and Recreation Administration, 19(4), 60-82.

Dobbs, D.B. (2000). The law of torts. St. Paul, MN: West Group.

Frame, J.D. (2003). Managing risk in organizations. San Francisco: Jossey-Bass.

Gillentine, A. (2003). Factors associated with participation in pre-game activities. Savannah, GA: Southern District American Alliance Health, Physical Education, Recreation, \& Dance.

Gillentine, A., \& Miller, J. (2006). The legal implications of tailgating. International Journal of Sport Management, 7(1), 102-111.

Gillentine, A., \& Miller, J. (2015). Tailgating meets entrepreneurship: The growth of a cottage industry. The Southern Sport Management Association Conference. Baton Rouge, LA.

Gillentine, A., Miller, J., \& Calhoun, A. (2008). Negligent marketing. What all sport marketers should know. Journal of Contemporary Athletics, 3(2), 161-172.

Gillentine, A., Miller, J., \& Crow, B. (2010). Developing a best practice model for tailgating events. Journal of Event \& Venue Management, 2(1), 54-68.

Grady, J. (2013). Premises liability. In D. Cotten \& J. Wolohan (Eds.), Law for recreation and sport Managers (5th ed., pp. 130-140). Durham, NC: Carolina Academic Press.

Grady, J., \& Andrew, D. (2007). Equality of access to emergency services for people with disabilities under the Americans with Disabilities Act. Journal of Legal Aspects of Sport, $17(1), 1-25$.

Grady, J., Andrew, D., Mercado, H., \& Blevins, J. (2015). Preparing for the baby boomer generation: Legal and managerial challenges for sport facility managers. Southern Sport Management Association Conference: Baton Rouge, LA.

Grady, J., \& Finnegan, M. (2012). London 2012 "Games Mobility”: Legal and managerial considerations in accommodating Olympic spectators with disabilities. Sport, Entertainment and Venues Tomorrow Conference. Columbia, SC.

Grady, J., \& Paramio, J. (2012). Global approaches to managing the fan experience for patrons with disabilities. Sport Marketing Association Conference. Orlando, FL.

Harford, T.C., Wechsler, H., \& Muthen, B.O. (2003). Alcohol-related aggression and drinking at off-campus parties and bars: A national study of current drinkers in college. Journal of Studies on Alcohol, 64(5), 704-711. doi:10.15288/jsa.2003.64.704

Holmes, O.W. (1881/1963). The common law. M. DeWolfe Howe (Ed.). Cambridge, MA: Harvard University Press.

James, J., Breezeel, G., \& Ross, S. (2001). A two-stage study of the reasons to begin and continue tailgating. Sport Marketing Quarterly, 10(4), 221-222.

Leuchovius, D. (2007, August 21). ADA Q \& A: Filing a complaint. Pacer Center. Retrieved from http://www.pacer.org/publications/adaqa/complaint.asp

Mann v. Shusteric Enters., 470 Mich. 320, 683 N.W.2d 573, 2004 Mich. LEXIS 1215 (2004).

McCormick, B.P. (2000). National Survey on recreation and the environment. National Center on Accessibility. Retrieved from http://www.indiana.edu/ nca/ rec-leisure/nsre.shtml

McPherson v. Tenn. Football Inc., 2007 U.S. Dist. LEXIS 39595 (M.D. Tenn. May 31, 2007).

Miller, J., \& Gillentine, A. (2006). An analysis of tailgating policies at Division I Universities. Journal of the Legal Aspects of Sport, 16(2), 197-215.

Miller, J.J., Wendt, J.T., \& Young, P.C. (2010). Fourth Amendment considerations and application of risk management principles for pat-down searches at professional football games. Journal of Legal Aspects of Sport, 20(2), 108-134.

Moorman, A.M., \& Grady, J. (2011). Legal research. In D.P.S. Andrew, P. M. Pedersen, \& C. McEvoy (Ed.), Research methods and design in sport management (pp. 173-195). Champaign, IL: Human Kinetics. 
Norman, M. (2012, Sept. 21). Judge allows suit over Gamecock football parking spaces to go forward. WISTV.com. Retrieved from http://www.wistv.com/story/18841697/ judge-allows-suit-over-gamecock-football-parking-spaces-to-go-forward

O'Toole, W.J. (2000). Towards the integration of event management best practice by the project management process. Events Beyond 2000. Retrieved from http://www.acem. uts.edu.au/pdfs/Events2000_finalversion.pdf\#page=92.

Paramio-Salcines, J. (n.d.). Interview with Phil Downs. Managing sport. Retrieved from http://www.managingsport.com/files/MgSport-Interview\%20Phil\%20Downs\%20 by\%20Juan\%20Luis\%20Paramio.pdf

Paramio-Salcines, J., Downs, P. \& Grady, J. (in press). Football and its communities: The celebration of Manchester United's ability suite. Soccer and Society.

Pate, J., Bemiller, J., \& Hardin, R. (2010). Reserved: Best practices for on-campus football parking for people with physical disabilities. Journal of Venue and Event Management, 2(1), 1-3 Retrieved from http://sc.edu/study/colleges_schools/hrsm/research/ research_jo and_publications/jvem_pdfs/vol12_no1/accessible_parking.pdf.

Piccarello, C.M. (2005). Terrorism, tourism, and torts: Liability in the event of a terrorist attack on a sports or entertainment venue. Villanova Sports and Entertainment Law Journal, 12, 365-392.

Quinlivan v. The Great Atlantic \& Pacific Tea Co., Inc., 395 Mich. 244, 266, 235 N.W.2d 732 (Mich. 1975).

Restatement (Second) of Torts (1969).

Rimmer, J.H. (2005). The conspicuous absence of people with disabilities in public fitness and recreation facilities: Lack of interest or lack of access? American Journal of Health Promotion, 19(5), 327-329. doi:10.4278/0890-1171-19.5.327

Rotolo v. San Jose Sports and Entertainment Enterprise, Inc., (2007) LEXIS 8772 (Cal., Aug. 15, 2007).

Ruof, M.C. (2004). Vulnerability, vulnerable populations, and policy. Kennedy Institute of Ethics Journal, 14(4), 411-425. doi:10.1353/ken.2004.0044

Seidler, T. (2005). Conducting a facility risk review. In H. Appenzeller (Ed.), Risk management in sport: Issues and Strategies (2nd ed.) (pp. 317-328). Durham, NC: Carolina Academic Press.

Schoepfer-Bochicchio, K. (2013). Sports venues facing more legal battles over captioning. AthleticBusiness.com. Retrieved from http://www.athleticbusiness.com/contract- law/ sports-venues-facing-more-legal-battles-over-captioning.html\#lightbox/0/

Staff report. (2014). Medical facility officials not sure they'll allow tailgaters after huge brawl before UTEP-Texas Tech game. KVIA.com. Retrieved from http://www.kvia. $\mathrm{com} /$ news/medical-facility-not-sure-it-will-allow-tailgaters-after-huge-brawl-beforeuteptex<unknown>as-tech-game/27942916.

Stone, D.H. (2007). You take my space, I take your air: An empirical study of disabled parking and motor vehicle laws for persons with disabilities. Ohio Northern University Law Review, 33, 665-713.

U.S. Department of Education. (2013). Dear Colleague Letter: Students with disabilities in extracurricular athletics (January 25, 2013). Retrieved from http://www2.ed.gov/about/ offices/list/ocr/docs/dcl-factsheet-201301-504.html.

Walsh, M. (2013). Star player rescues man in wheelchair nearly trampled by joyous North Carolina State basketball crowd. Retrieved from http://www.nydailynews.com/news. com/news/national/hoop-star-saves-wheelchair-bound-fan-victory-celebration-trampling-article-1.1240623.

Williams, C.A., Smith, M.L., \& Young, P.C. (1998). Risk management and insurance (8th ed.). New York: McGraw-Hill Book Company.

Wong, G.M. (2002). Essentials of sports law. Westport, Ct.: Praeger Publishers.

World Health Organization. (2015). Vulnerable groups. Retrieved from http://www.who. int/envi ronmental_health_emergencies/vulnerable_groups/en/. 